\title{
Regulation of malignant phenotype and bioenergetics by a $\pi$-electron donor-inducible mitochondrial MgATPase
}

\author{
ERNEST KUN $^{1}$, JEROME MENDELEYEV ${ }^{1}$, EVA KIRSTEN $^{1}$, ALAEDDIN HAKAM ${ }^{1}$, ALBERT M. KUN ${ }^{1}$, \\ ANNA FEKETE $^{2}$, PAL I. BAUER ${ }^{2}$, ZSUZSANNA DUNAI $^{3}$ and RUDOLF MIHALIK ${ }^{3}$ \\ ${ }^{1}$ Department of Anatomy, UCSF Helen Diller Family Comprehensive Cancer Center and the Department of Cellular and \\ Molecular Pharmacology, University of California, School of Medicine, San Francisco, CA 94143, USA; \\ ${ }^{2}$ Department of Medical Biochemistry, Semmelweis University, 1094 Budapest; ${ }^{3}$ Department of First \\ Pathology and Experimental Cancer Research, Semmelweis University, 1085 Budapest, Hungary
}

Received September 10, 2010; Accepted October 25, 2010

DOI: $10.3892 / \mathrm{ijmm} .2010 .567$

\begin{abstract}
The recognition of poly ADP-ribose transferase-1 (PARP-1) as an ATP sensor receiving this energy source by way of a specific adenylate kinase ATP wire (AK) from mitochondrial ATP synthase $\left(\mathrm{F}_{0} \mathrm{~F}_{1}\right)$, and directly regulating cellular mRNA and DNA synthesis, was the first step towards the identification of an effect by PARP-1 that is of fundamental significance. The molecular target of AK-ATP is Arg 34 of the $\mathrm{Zn}$ finger I of PARP-1, which is also a site for cation- $\pi$ interactions as a target of $\pi$-electron donors. We now identify this $\pi$-electron receptor site as the second active center of PARP-1 which by interaction with a $\pi$-electron donor-inducible MgATPase reversibly controls a malignant vs. non-malignant phenotype through energizing the $\mathrm{NADH} \rightarrow \mathrm{NADP}^{+}$transhydrogenase, a reaction which is the metabolic connection of PARP-1 to cell function. The specific enzyme-inducing action of the $\pi$-electrons is executed by the PARP-1 -topoisomerase I - DNA complex of the nuclei regulating both the nature and the quantity of cellular enzymes that constitute cell-specific physiology.
\end{abstract}

Correspondence to: Professor Ernest Kun, Helen Diller Family Comprehensive Cancer Center, Box 0452, University of California San Francisco, San Francisco, CA 94143, USA

E-mail: ernestkun@comcast.net

Abbreviations: PARP-1, poly ADP-ribose transferase (EC 2.4.2.30); MgATP, adenosine triphosphate Mg complex; Topo I, topoisomerase I; AK, adenylate kinase; OXPHOS, oxidative phosphorylation; AI, 6-amino indole; $\mathrm{F}_{0} \mathrm{~F}_{1}$, mitochondrial ATP synthase; $\mathrm{AcPyNAD}^{+}$, acetylpyridine $\mathrm{NAD}^{+}$; $\mathrm{TH}$, transhydrogenase; DMSO, dimethylsulfoxide; FCCP, carbonyl cyanide 4(trifluoromethoxy)phenylhydrazone

Key words: MgATPase, energy transduction to NADH $\rightarrow \mathrm{NADP}^{+}$ transhydrogenation, $\pi$-electron donors

\section{Introduction}

Immunochemical (1) and catalytic (2) determination of the molar concentrations of ADP-ribose oligomers and of poly ADP-ribose transferase-1 (PARP-1), which under normal conditions have an oligo-ADP-ribose per PARP-1 ratio of no more than $1 / 10$, suggests a second, heretofore undefined cellular function of PARP-1. The nature of this second active site of PARP-1 is elucidated here with the aid of an experimental approach that avoids the violation of cellular integrity.

Reversible permeabilization of the cell wall with lysolecithin (LL) permits the measurement of RNA, DNA and protein synthesis rates in cells which show no structural deformity determined by electron microscopy (3). This technique led to the discovery of the guanidinium center of Arg 34 of $\mathrm{Zn}^{2+}$ finger I of PARP-1. This center regulates cellular replication and phenotype in two modes: a) specific for normal energy-coupled cells controlling mRNA and DNA synthesis (4), and b) a tumor cell-specific action of $\pi$-electron donors that causes reversible phenotypic transformation to non-tumor cells, as reported here. Regulatory path a) consists of a mitochondrial-nuclear signal transfer of ATP by way of adenylate kinase-bound ATP (AK-ATP) exerting a direct effect on PARP-1 activity at the Arg 34 site, identified by a point mutation of $\mathrm{Zn}^{2+}$ finger I of PARP-1 $(5,6)$. This pathway utilizes unhydrolyzed ATP to inhibit auto-oligo ADPribosylation of PARP-1 with simultaneous activation of topoisomerase I (Topo I) through binding of PARP-1 at an amino acid sequence-specific activating site of Topo I (5) or at an inhibitory site (7) when oxidative phosphorylation (OXPHOS) is uncoupled, demonstrating energy-dependent control of mRNA synthesis (4). The biosynthesis of DNA is also regulated by OXPHOS as follows. The energy source of DNA synthesis in the LL system is ATP generated by nuclear glycolysis (8), and the rate limiting step of this pathway is hexokinase, which is controlled by trans-ADP-ribosylation. Trans-ADP-ribosylation to histones (9) has further important consequences by the modifying the chromatin structuredependent selection of DNAs for the site-specific activation 
of Topo I for DNA transcription (7). It is this site, which responds to $\pi$-electron binding-induced biosynthesis of the energy transducing MgATPase.

When AK-ATP is absent such as in the case of cells in which OXPHOS is uncoupled, the free guanidinium center of Arg 34 functions as a site for the binding of $\pi$-electron rich molecules (10-12). It follows that the enzyme protein PARP-1, as a nuclear receptor, contains two distinct active sites: a) the $\mathrm{NAD}^{+}$-derived ADP-ribose transferring site and b) a $\pi$-electronsensitive guanidinium center, which connects PARP-1 with energy-coupled cellular regulation. Identification of these two PARP-1 sites depends on the application of site-specific reagents. The observation that nicotinamide site-oriented aromatic drugs $(3,13)$ also elicited large phenotypic cellular changes, could not be explained by effects exerted on ADPribosylation of proteins only. This question was clarified by the study of a typical $\pi$-electron donor, 6-aminoindole (AI), on cell function. Cellular responses elicited by AI were discriminated from those caused by benzamides and benzopyrones because AI had no effect on the ADP-ribose transfer from $\mathrm{NAD}^{+}$to protein acceptors (results not shown). On the other hand, the ADP-ribosylation inhibitors containing aromatic structures can also serve as $\pi$-electron donors; thus, an inhibitory action on ADP-ribosylation and a $\pi$-electron donor property can co-exist in the same molecule. The PARP-1 inhibitor, 5-iodo-6-amino-1-2-benzopyrone $\left(\mathrm{INH}_{2} \mathrm{BP}\right)$ (3), exerts an inhibitory effect on ADP-ribose transfer and can serve as a $\pi$-electron donor as well. We found that $\mathrm{AI}$ and $\mathrm{INH}_{2} \mathrm{BP}$ can both induce the energy coupling of the $\mathrm{NADH} \rightarrow$ $\mathrm{NADP}^{+}$transhydrogenation. However, cell survival critically depends also on the induction of additional enzymes, in this case alkaline phosphatase induction by $\mathrm{INH}_{2} \mathrm{BP}$ (3), which dephosphorylates proteins dependent on protein phosphorylation, resulting in cell death.

\section{Materials and methods}

6-Aminoindole and its analogs, Brij 58, nucleotides and other reagents such as benzo(a)pyrone, BSO (buthionine sulfoximine) and buffer reagents all of analytical grade were obtained from Sigma-Aldrich. 4-Iodo-3-nitrobenzamide was synthesized as previously reported $(3,29)$. Cellular proteins were analyzed as reported (4). CV-1 and E-ras 20 cells were cultured as referenced in this paper, and LL-permeabilization was performed as reported (14). For protein analyses of E $\pi$ cells logarithmically growing E-ras 20 cells $\left(10^{6}\right.$ cells exposed to $200 \mu \mathrm{M}$ AI for 5 days) were fractionated into soluble ( $\mathrm{Su})$ and particulate $(\mathrm{Mx})$ by the LL technique (14). The Mx fraction was resuspended in LL buffer $(500 \mu 1)$ for $5 \mathrm{~min}$, then washed by sedimentation at $3000 \mathrm{rpm}$ (Eppendorf microfuge) at $4^{\circ} \mathrm{C}$ for $5 \mathrm{~min}$ and resuspended in $200 \mu \mathrm{LL}$ buffer containing $1 \%$ Brij 58, kept on ice for $5 \mathrm{~min}$, then sedimented at $12,000 \mathrm{rpm}$. The supernatant contained the Brij 58 extract, which was mixed with an equal volume of Laemmli buffer. Proteins were separated in 10\% SDS-PAGE gel and stained with Coomassie blue. Each induced band was extracted following the protocol of the MS laboratory and analyzed by MALDI-TOF for amino acid sequences at the UCSF Sandler Moore Mass Spectrometry Core facility, acknowledging support from NIH/NCI Cancer Center

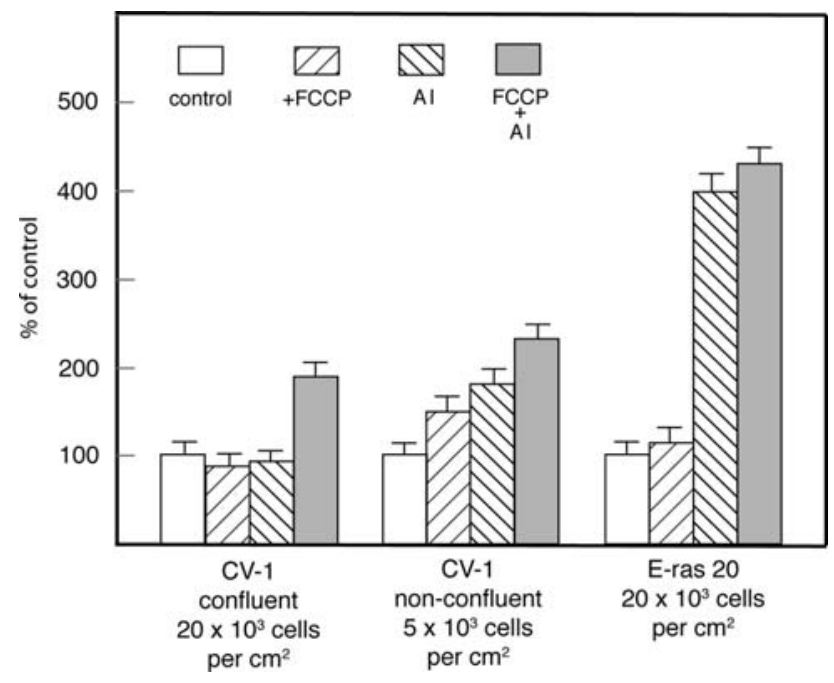

Figure 1. 6-Amino indole (AI)-activated and $\pi$-protein supported MgATPdependent $\mathrm{NADH} \rightarrow \mathrm{NADP}^{+}$transhydrogenase activity in three cellular phenotypes. Results were normalized to $100 \%$ of control. FCCP, when applied, was $8 \mu \mathrm{M}$ for $2 \mathrm{~h}$; AI $100 \mu \mathrm{M}$ for 2 days. A description of the optical test systems is described in Kun et al (14), $\mathrm{n}=3, \mathrm{SD} \pm 8 \%$ of mean. All values are calculated as $\Delta \mathrm{A}_{340 \mathrm{~nm}}$ per $10^{6}$ cell equivalent

support grant (P30CA82103), the Sandler Family Foundation and the Gordon and Betty Moore Foundation. Spectrophotometric assays were performed as previously reported (14). The $1 \%$ Brij 58 extract of the permeabilized cells was used; i.e. $1 / 10$ volume of $10 \%$ Brij 58 was added to the $0.21 \mathrm{mg} / \mathrm{ml}$ LL suspension of cells, and the centrifugal supernatant of this mixture constituted the assay system. Cellular $\mathrm{O}_{2}$ uptake kinetics were measured as described in the legend of Fig. 3, and cell sorting as described in the legend of Fig. 2. Nonspecific cellular toxicity of AI was ruled out by the trypan blue exclusion test.

\section{Results and Discussion}

The energy source for $N A D H \rightarrow N A D P^{+}$transhydrogenation is MgATP hydrolysis. As previously reported (14) the LL method generates two distinct cell fractions, separated by centrifugation: a Su and an Mx fraction. The Su fraction had energyindependent transhydrogenase enzyme activity that transferred $\mathrm{H}$ from NADPH to acetylpyridine $\mathrm{NAD}^{+}\left(\mathrm{AcPyNAD}^{+}\right)$or $\mathrm{NAD}^{+}$, an enzyme activity that showed no variation between non-malignant (CV-1) and malignant (E-ras 20) cells and was uninfluenced by MgATP when assayed in this direction, i.e. from NADPH to AcPyNAD ${ }^{+}$. Incubation of malignant E-ras 20 cells with 100-150 $\mu \mathrm{M}$ AI for 2 days greatly increased the activation of $\mathrm{NADH} \rightarrow \mathrm{NADP}^{+}$transhydrogenation induced by Brij 58 extracts made from these cells, an increase that was abolished by the protein synthesis inhibitor cycloheximide (60-90 $\mu \mathrm{M})$, thereby identifying the effect of AI as enzyme induction.

Mitochondria contained in the Mx fraction (see Materials and methods) were extracted with a $1 \%$ aqueous solution of Brij 58. This extract had an AI-inducible MgATPase that was isolated by 2D gel electrophoresis (160-170 kDa, nondenaturing gel) dissociating in 3 unequal subunits in an SDS 
Table I. Effect of 6-amino indole on growth and transhydrogenation rates of various human cancer cells.

\begin{tabular}{lccc}
\hline Cell type & $\begin{array}{c}\text { Growth inhibition } \\
(\%)\end{array}$ & $\begin{array}{c}\text { TH rate (no treatment) } \\
(\mathrm{nmol} / \mathrm{min})\end{array}$ & $\begin{array}{c}\text { TH rate (treatment with 6-AI) } \\
(\mathrm{nmol} / \mathrm{min})\end{array}$ \\
\hline $\begin{array}{l}\text { HeLa } \\
\text { (cervical cancer) }\end{array}$ & 80 & 0.44 & 1.49 \\
$\begin{array}{l}\text { Calu-6 } \\
\text { (bronchial cancer) }\end{array}$ & 80 & 0.21 & 0.60 \\
$\begin{array}{l}\text { Scov-3 } \\
\text { (ovarian cancer) }\end{array}$ & 70 & 0.48 & 0.82 \\
$\begin{array}{l}\text { MDA-231 } \\
\text { (breast cancer) }\end{array}$ & 90 & 0.44 & 1.19 \\
$\begin{array}{l}\text { Du-145 } \\
\text { (prostate cancer) }\end{array}$ & 80 & 1.27 & 2.24
\end{tabular}

All malignant phenotypes were converted to non-malignant ones. The MgATPase- $\pi$ protein content of all tumor cells was nearly the same; $\mathrm{n}=3, \mathrm{SD} \pm 10 \%$. $\mathrm{TH}$, transhydrogenation; AI treatment, $150 \mu \mathrm{M}$ for 2 days.

gel and identified by sequencing (MALDI-TOF). There is a $22.5 \%$ homology measured with more than $99 \%$ accuracy between the isolated protein and subunit a of the Na-K transporting ATPase (NOBI protein data bank accession number QO8DAL, species bos taurus). The MgATPase activity was $14.2 \mathrm{nmols}$ of ATP hydrolyzed/mg/min. The enzyme is specific for MgATP. MgATP is provided by the OXPHOS-independent mitochondrial Mg-ATP pump (15). The excited MgADP being phosphorylated by glycolytic ATP to MgATP is then the available energy source for $\mathrm{NADH} \rightarrow \mathrm{NADP}^{+}$transhydrogenation as shown in the equation:

$$
\begin{gathered}
\mathrm{NADH}+\mathrm{NADP}^{+}+\mathrm{MgATP}+\mathrm{H}_{2} \mathrm{O} \rightarrow \\
\mathrm{NAD}^{+}+\mathrm{NADPH}+\mathrm{MgADP}+\mathrm{Pi} \\
\Delta \mathrm{G}=-4.48 \mathrm{Kcal} / \mathrm{mol}
\end{gathered}
$$

From known NADP ${ }^{+} / \mathrm{NADPH}$ ratios being $1 / 10$ and $\mathrm{NAD}^{+} / \mathrm{NADH}$ ratios being $10 / 1$, a $\Delta \mathrm{G}$ of $2.72 \mathrm{Kcal}$ can be calculated, this being positive in the endergonic direction. Therefore, energy generated by the hydrolysis of MgATP is sufficient for NADPH formation.

The MgATP-driven NADH $\rightarrow \mathrm{NADP}^{+}$transhydrogenation can be assayed by either added AcPyrNADH or metabolically generated cellular $\mathrm{NADH}$ as a $\mathrm{H}$ donor (14). In the latter assay glutamate $(5 \mathrm{nmol} / \mathrm{mg}$ mitochondrial protein) (15) was found to be the universal substrate that reduced $\mathrm{NAD}^{+}$present in the $\mathrm{Su}$ fraction at a $1 \mu \mathrm{M}$ concentration.

Correlation between cell growth bioenergetics and transhydrogenase activities. Non-growing, confluent CV-1 cells (Fig. 1) showed transhydrogenase rates which were not affected by the uncoupler FCCP or by the $\pi$-electron donor AI when these reagents were added individually. However, significant enzyme induction by AI in 2 days was seen following uncoupling with FCCP. Uncoupling with FCCP allows the entrance of AI to the guanidinium center, a condition necessary for enzyme induction by AI. Exponentially growing CV-1 cells (Fig. 1) behaved as if they were partially uncoupled. Preincubation with FCCP further magnified enzyme induction by AI, demonstrating that physiologic uncoupling was about $50 \%$. The energy coupling by $\pi$-protein with transhydrogenase activity in E-ras 20 cells, which show uncontrolled growth phenotype, was greatly induced by AI, again demonstrating that the guanidinium center of Arg 34 was readily accessible to the $\pi$-electron donor when the gate-keeping role of ATP was absent in uncoupled cells. This was the case in the cancer cells studied thus far (Table I).

Localization of the receptor site on PARP-1. This was done by experiments with $\mathrm{PARP}^{-/-}$fibroblasts (P.I. Bauer, unpublished results). $\mathrm{PARP}^{-/}$fibroblasts and their $\mathrm{PARP}^{+}$counterparts, plated at $0.5 \times 10^{6}$ cells/plate, grew at the same rate. However, exposure (3 times weekly for $4 \mathrm{~h}$ during a period of 3 weeks) to the chemical carcinogens methylnitronitrosoguanidine $(17 \mu \mathrm{M})$ or benzo(a)pyrene $(2.6 \mu \mathrm{M})$, each dissolved in DMSO, converted $\mathrm{PARP}^{-/-}$fibroblasts to a malignant phenotype as assayed by colony formation (13). This carcinogeninduced malignant phenotype could not be reverted to the non-malignant cell type by incubation with $100 \mu \mathrm{M}$ AI. Clearly, while chemical carcinogenesis requires no PARP-1, the presence of PARP-1 was necessary for phenotypic reversion, demonstrating the location of the AI site in PARP-1. It is striking that PARP ${ }^{-/}$cells are hypersensitive to chemical carcinogens.

Inhibition of cell multiplication by AI. The largest effect of AI was observed with E-ras 20 cancer cells (Table I). Their doubling time was $8 \mathrm{~h}$ in the absence of AI, while cessation of cell multiplication occurred after incubation with $150 \mu \mathrm{M}$ AI for 2 consecutive days when E-ras 20 cells were seeded at a cell density of $20 \times 10^{3}$ cells $/ \mathrm{cm}^{2}$. Non-confluent logarithmically growing CV-1 cells (Fig. 1), when exposed to $150 \mu \mathrm{M}$ 


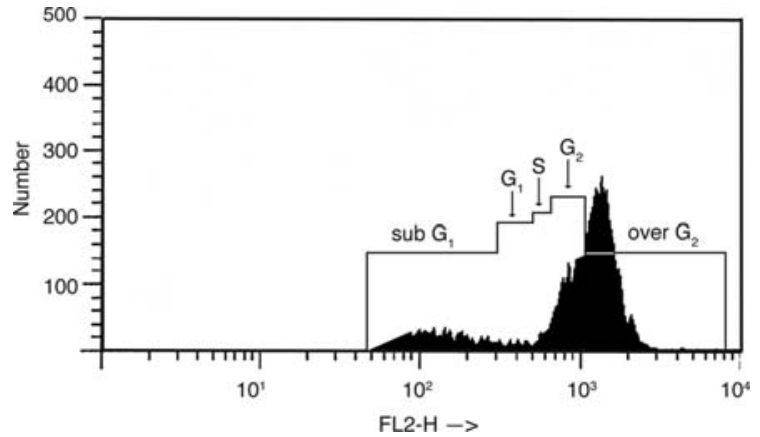

Figure 2. Inhibition of the cell growth cycle by incubation of E-ras 20 cells with $100 \mu \mathrm{M}$ AI for 5 consecutive days. FACS analysis demonstrates a G2 and over $\mathrm{G} 2$ phase block; $\mathrm{n}=3, \mathrm{SD} \pm 8 \%$ of the mean.

AI responded in the same way as E-ras 20 cells with inhibition of cell replication even though their doubling time in the absence of AI was $34 \mathrm{~h}$. On the other hand, confluent CV-1 cells, which exhibited contact inhibition were unaffected by $\mathrm{AI}$ even at $600 \mu \mathrm{M} \mathrm{AI}$, demonstrating that the site of action of the $\pi$-electron donor AI is the ATP-free guanidinium center of Arg 34 (not shown).

Cell cycle analyses of E-ras 20 cells following exposure of these cells to $100 \mu \mathrm{M}$ AI for 5 consecutive days. Cell cycle analyses (16) demonstrated G2 and over G2 phase block (Fig. 2), which explain the inhibition of cell replication. As we have reported (4), sustained uncoupling of OXPHOS as it exists in the malignant phenotype derepresses nuclear glycolysis at the hexokinase site, thereby speeding up nuclear glycolytic ATP synthesis and accelerating DNA synthesis in tumor cells, leading to aneuploid DNA, which is a well-known phenotypic property of cancer cells (17).

Cell enlargement and reversibility of the action of AI. Incubation of E-ras 20 cells with AI induces a rapid cell enlargement but only a marginal (statistically non-significant) increase in protein content. On the other hand, the induction of the enzymes required for the oxidation of added NADH following treatment of E-ras 20 cells with AI is readily measurable by the kinetics of $\mathrm{O}_{2}$ uptake (Fig. 3), because catalytic tests for protein activity provide a far more sensitive quantitation of a protein molecule than the methods based on the chemical assay of the protein. Cellular enlargement occurred as a consequence of 2 and 7 days of AI treatment from $2.3 \mu 1 / 10^{6}$ cells to $7-10 \mu 1 / 10^{6}$ cells. The enlarged cells $(\pi$ cells) remained viable in the presence of AI for 10 consecutive days. The in vivo fate of these cells ( $\pi$ cells) is as yet unknown. The cellular actions of AI are reversible. Removal of AI resulted in a decrease of transhydrogenase activity, concomitant with the return of the malignant phenotype. From these results the lifetime of the $\pi$-protein was estimated to be 1.5-2 days. AI is not a cellular component, but rather a pharmacologic probe; however, other physiologic $\pi$-electron donors in various cell types may act on selected $\pi$-sensitive sites and may contribute to the metabolic diversity that exists between different cell types. This diversity depends on the electrostatic surface potential of $\pi$-electron donors (12).
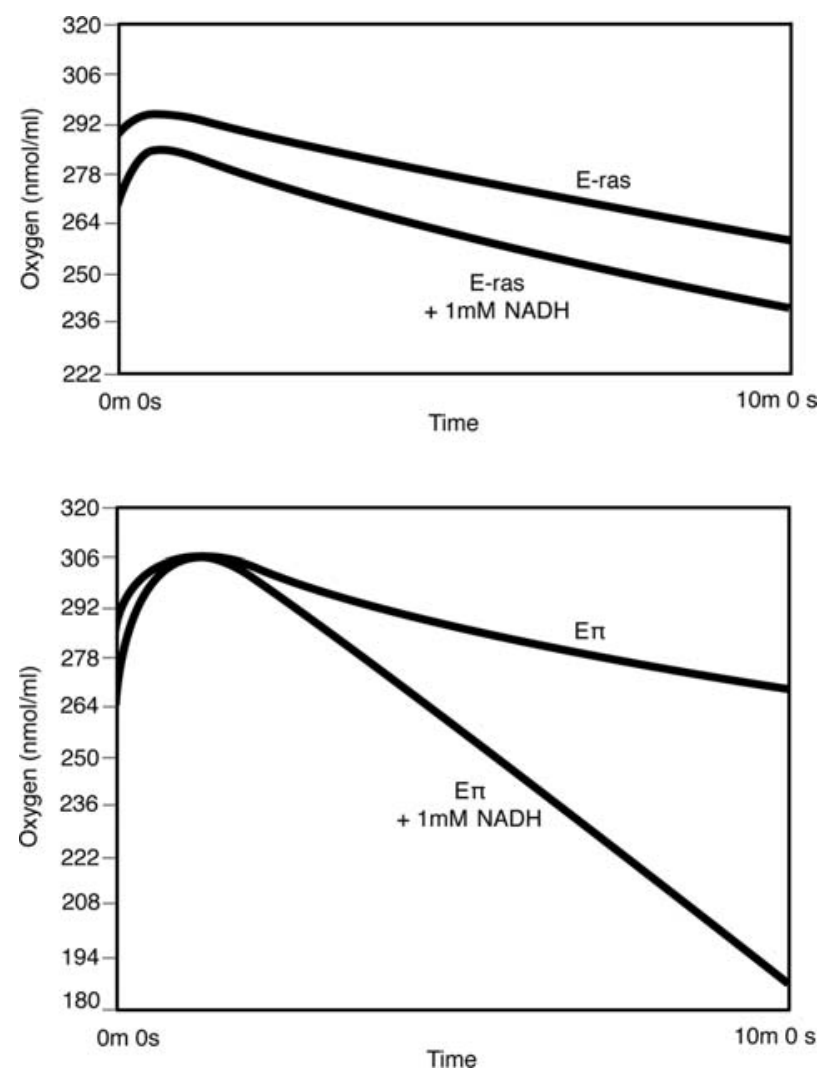

Figure 3. Oxygen uptake by E-ras and E $\pi$ cells. Measurements were made in a Hansatech Oxytherm oxygen meter. Cells were harvested, treated with LL as published, and suspended in LL. All measurements were made with $1 \times 10^{6}$ cells in $500 \mu 1 \mathrm{LL}$ buffer at $25^{\circ} \mathrm{C}$. As shown, addition of $1 \mathrm{mM}$ NADH dramatically increases oxygen uptake in E $\pi$ cells, but not in E-ras cells. Triplicate tests, with $\mathrm{SD} \pm 10 \%$.

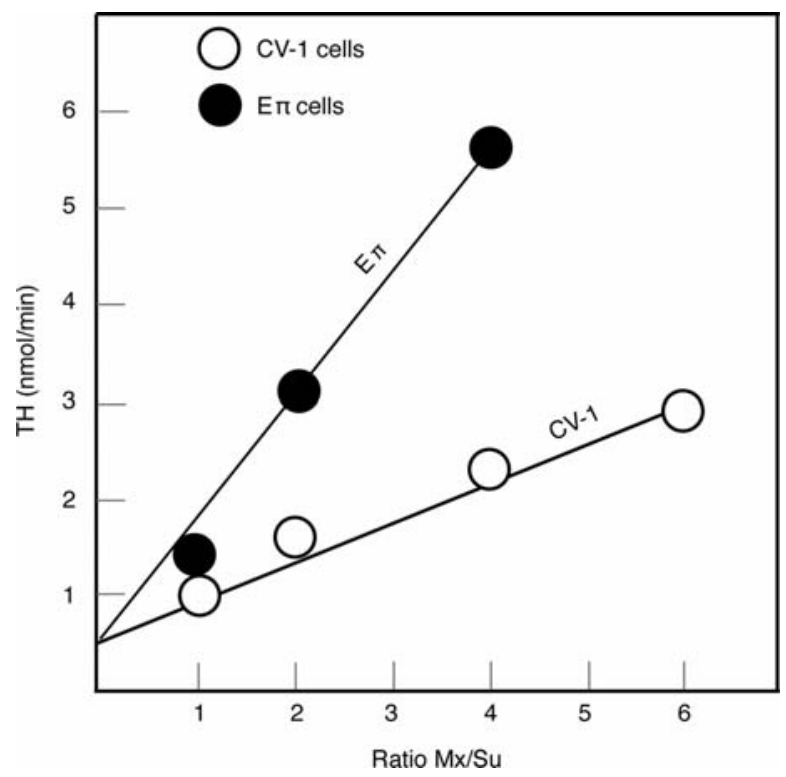

Figure 4. Linear correlation between the activation of MgATP-dependent transhydrogenation and the quantity of AI induced protein in E-ras 20 cells (upper curve). The lower curve shows the effect of endogenous $\pi$-electron donor(s) in CV-1 cells that were not induced by AI. Triplicate tests with $\mathrm{SD} \pm 6 \%$. Ordinate: $\mathrm{TH}$ is the MgATP-dependent transhydrogenation (nmol $\mathrm{NADPH} / \mathrm{min}$ ). Abscissa: $\mathrm{Mx} / \mathrm{Su}$ is the Brij 58 extract from varying quantities of $\mathrm{Mx}$, the extract containing the $\pi \mathrm{MgATPase}$ at constant amounts of $\mathrm{Su}$. 
Proportionality between the quantity of added $\pi$-ATPase and transhydrogenase rates in E-ras 20 cells and evidence for $\pi$-electron donors in CV-1 cells. As illustrated in the upper linear rate portion of Fig. 4, there is a linear proportionality of activation by $\pi$-protein on enzymatic rates, supporting the energy donor function of MgATP protein as described in the equation. The lower curve of Fig. 4 was obtained by the graded addition of Brij 58 extract (containing $\pi$-protein) of the $\mathrm{Mx}$ fraction prepared from CV-1 cells untreated by AI. The linear activation of transhydrogenase by the extract of $\mathrm{CV}-1$ cells demonstrates the existence of one or more AI-like components in non-malignant cells also.

AI-induced NADH oxidation in E-ras 20 cells previously exposed to AI for 2 days. The LL-permeabilized cells exhibit rates of $\mathrm{O}_{2}$ consumption, measured by a highly sensitive polarographic technique (see Materials and methods) that is as low as $1-5 \%$ of the rate obtained in respirometers, demonstrating that structural integrity exerts strong metabolic control, characteristic of physiologically functioning cells. Only externally added NADH but not NADPH (results not shown) is directly oxidized by E- $\pi$ cells (E-ras 20 cells induced by AI for 2 days), demonstrating the coincidence of induction of the MgATPase ( $\pi$-ATPase) and NADH oxidation.

Comparison of respiratory enzyme content of malignant and non-malignant cells. Interpretation of our experiments critically depends on the quantity of respiratory enzymes in malignant cells. This was directly determined by quantitative gel electrophoresis of respiratory chain complexes (18) and comparison of mitochondrial content as assayed with citrate synthase activity (19). No significant differences were detectable between non-malignant $(\mathrm{CV}-1)$ and cancer (HeLa cells (negative results not shown).

Based on previous results and those reported here, the biochemistry of cell function can be reformulated as follows. Glycolysis probably provides the majority of ATP required for cell life (22). The central operation of the ATP synthase of mitochondria $(23,24)$ is more selectively confined to a direct cellular regulation by the nuclear receptor operative in PARP-1 which connects bioenergetics with macromolecular metabolism. Results in Fig. 1 demonstrate a direct regulation of $\mathrm{F}_{0} \mathrm{~F}_{1}$ by uncoupling cellular components which transiently exist in logarithmically growing cells, but vanish as soon as contact inhibition is reached. This regulation of cellular energy economy is mediated by biologic uncouplers formed only in proliferating cells.

The theory of defective cellular respiration as the basis of tumor metabolism was deduced from studies done with tissue slices (20). Our results directly contradict this theory because respiratory enzyme contents of non-malignant and tumor cells do not differ significantly. The only difference is the inducibility of the $\pi$-ATPase by $\pi$-electron donors, an event which removes malignant phenotype so long as the cell is supplied with the $\pi$-electron donor. This phenomenon identifies the $\pi$-electron donor as a transient tumor suppressor. Clearly, the problem of carcinogenesis and its reversal is now relegated to mechanisms of $\pi$-electron donor-initiated specific protein synthesis and to the biosynthesis of cell specific $\pi$-electron donors themselves, a research we are pursuing. The cellular significance of PARP-1 is apparent by way of its nuclear receptor function defining $\mathrm{Zn}^{2+}$ finger I as a regulator. The role of $\mathrm{Zn}^{2+}$ finger II is most likely a topologic control of positioning PARP-1 in DNA domains (21).

Retroviral mechanisms. The retrovirus HIV contains the same asymmetric $\mathrm{Zn}^{2+}$ finger as eukaryotic PARP-1 and is inactivated by the half-reduced prodrug (25) which is cytocidal to retroviral oncogene-driven tumor cells $(26,27)$. However, this direct inactivation is not the biochemical basis of antiHIV effectivity. A comparison of anti-HIV effect of nitrosogroup containing molecules with their prodrug, i.e. the nitrosubstituted species, demonstrates that retroviral infection induces cellular reduction of nitro- to the nitroso-species (28) a reaction which specifically exists in tumor cells (14). Retroviral infection therefore, induces deletion of $\pi$-ATPase and converts cells to the malignant phenotype that is susceptible to the tumoricidal prodrug (28). Cure of retroviral infection (e.g. by immunology) reconverts the cell to the normal phenotype because a cell-specific $\pi$-electron donor re-induces $\pi$-ATPase. Oncogenic retroviral infection may differ from other retroviruses by containing an additional genomic deletion for a $\pi$-electron donor. It is predictable that the pro-drug 4-iodo-3-nitrobenzamide (iniparib), after lowering cellular GSH content (29) will be effective in the chemotherapy of both cancer and HIV.

\section{Acknowledgments}

It is a pleasure to thank Clementina Moya Kun for editorial help. The Department of Anatomy, UCSF, provided financial support.

\section{References}

1. Minaga T, Romanschin A, Kirsten E and Kun E: The in vitro distribution of immunoreactive larger than tetrameric polyadenosine diphosphoribose in histone and non-histone protein fractions of rat liver. J Biol Chem 254: 9663-9668, 1979.

2. Kun E, Kirsten E, Bauer PI and Ordahl CP: Quantitative correlation between cellular proliferation and nuclear poly (ADP-ribose) polymerase (PARP-1). Int J Mol Med 17: 293-300, 2006.

3. Bauer PI, Kirsten E, Young LJT, Varadi G , Csonka E, Buki KG, Mikala G, Hu H, Comstock JA, Mendeleyev J, Hakam A and Kun E: Modification of growth related enzymatic pathways and apparent loss of tumorigenicity of a ras-transformed bovine endothelial cell line by treatment with 5 -iodo-6-amino-1,2benzo(a)pyrone (INH2BP). Int J Oncol 8: 239-252, 1996.

4. Kun, E, Kirsten E, Hakam A, Bauer PI and Mendeleyev J: Identification of poly(ADP-ribose) polymerase-1 as the OXPHOS-generated ATP sensor of nuclei of animal cells. Biochem Biophys Res Commun 366: 568-573, 2008.

5. Bauer PI, Kenesi E, Mendeleyev J and Kun E: The influence of ATP on poly(ATP-ribose) metabolism. Int J Mol Med 16: 321-324, 2005.

6. Bauer PI, Buki KG, Comstock JA and Kun E: Activation of topoisomerase I by poly(ADP-ribose)polymerase. Int J Mol Med 5: 533-540, 2000.

7. Bauer PI, Chen H-J, Kenesi E, Kenessey I, Buki KG, Kirsten E, Hakam A, Hwang JI and Kun E: Molecular interaction between poly(ADP-ribose) polymerase (PARP-1) and topoisomerase (Topo I). Identification of topology and binding. FEBS Lett 506: 239-242, 2001.

8. Kun E, Kirsten E, Hakam A, Bauer PI and Mendeleyev J: Dependence of trans-ADP-ribosylation and nuclear glycolysis on the Arg 34-ATP complex of $\mathrm{Zn}^{2+}$ finger I of poly (ADPribose) polymerase-1. FEBS Lett 582: 2709-2713, 2008. 
9. Buki KG, Bauer PI, Hakam A and Kun E: Identification of domains of poly (ADP-ribose) polymerase for protein binding and self-association. J Biol Chem 270: 3370-3377, 1995.

10. Burley SK and Petsko GA: Amino-aromatic interactions in proteins. FEBS Lett 203: 139-143, 1986.

11. Zacharias $N$ and Dougherty DA: Cation- $\pi$ interactions in ligand recognition and catalysis. Trends Pharmacol Sci 23: 281-287, 2002 .

12. Mecozzi S, West AP Jr and Dougherty D: Cation- $\pi$ interactions in aromatics of biological and medicinal interest: Electrostatic potential surfaces as a useful qualitative guide. Proc Natl Acad Sci USA 93: 10566-10571, 1996.

13. Kun E, Kirsten E, Milo GE, Kurin P and Kumari HL: Cell cycle dependent intervention by benzamide of carcinogen-induced neoplastic transformation and in vitro poly ADP-ribosylation of nuclear proteins in human fibroblasts. Proc Natl Acad Sci USA 80: 7219-7223, 1983

14. Kun E, Mendeleyev J, Hakam A and Kirsten E: Enzymatic mechanism of the tumoricidal action of 4-iodo-3-nitrobenzamide. Mol Med Rep 2: 739-742, 2009.

15. Kun E: Kinetics of ATP-dependent $\mathrm{Mg}^{2+}$ flux in mitochondria. Biochemistry 15: 2328-2335, 1976.

16. Mihalik R, Uher F, Pocsik EE, Berczi L, Benczur M an Kopper L: Detection of drug-induced apoptosis by flow cytometry after alkaline extraction of ethanol fixed cells. Pathol Oncol Res 2: 78-83,1996.

17. Holland AJ and Cleveland DW: Boveri revisited: chromosoma instability, aneuploid tumorigenesis. Nat Rev Mol Cell Biol 10 478-487, 2009.

18. Rustin P, Chretien D, Bourgeron T, Gerard B, Rotig A, Saudubray FM and Munnich A: Biochemical and molecular investigations in respiratory chain deficiencies. Clin Chem Acta 228: 35-51, 1994.
19. Srere PA: Citrate synthase. Methods Enzymol 13: 3-11, 1969.

20. Warburg O: On the origin of cancer cells. Science 123: 309-314, 1956.

21. Huang K, Tidyman WE, Le KUT, Kirsten E, Kun E and Ordahl CP: Analysis of nucleotide sequence-dependent DNA binding of poly(ADP-ribose)polymerase in a purified system. Biochemistry 43: 217-223, 2004.

22. Voet D and Voet JG: Biochemistry. 2nd edition. John Wiley and Sons, Inc., New York, pp469-595, 1995.

23. Boyer PD: Energy, life, and ATP. Angew Chem Int Ed 37: 2296-2307, 1998.

24. Walker JE: ATP synthesis by rotary catalysis. Angew Chem Int Ed 37: 3209-2318, 1998

25. Rice WR, Schaeffer CA, Harten B, Villinger F, South TL, Summers MF, Henderson LE, Bess JW Jr, Arthur LO, McDougal JS, Orloff SL, Mendeleyev J and Kun E: Inhibition of HIV-1 infectivity by zinc-ejecting aromatic C-nitroso compounds. Nature 361: 473-475, 1993.

26. Varmus HE: Retroviruses and oncogenes I. Angew Chem Int Ed 29: 707-715, 1990

27. Bishop JM: Retroviruses and oncogenes II. Angew Chem Int Ed 29: 716-724, 1990.

28. Chuang AJ, Killam KF, Chuang RY, Mendeleyev J and Kun E: Comparison of the cytotoxic and antitretroviral effects of 3nitrosobenzamide and 4-iodo-3-nitrobenzamide. Proc West Pharmacol Soc 37: 117-119, 1994.

29. Bauer PI, Mendeleyev J, Kirsten E, Comstock JA, Hakam A, Buki KG and Kun E: Anti-cancer action of 4-iodo-3-nitrobenzamide I combination with butionine sulfoximine: inactivation of poly (ADP-ribose) polymerase and tumor glycolysis and the appearance of a poly (ADP-ribose) polymerase protease. Biochem Pharmacol 63: 455-461, 2002. 